\title{
A LA BÚSQUEDA DEL MÉDICO BUENO: LOS CONFLICTOS DE INTERESES EN LAS RELACIONES CON LA INDUSTRIA FARMACÉUTICA
}

\author{
IRENE VERDÚ GONZÁLEZ \\ Magíster en Bioderecho \\ Universidad de Murcia \\ irene.verdu@um.es
}

Fecha de recepción: 04/12/2020 - Fecha de aceptación: 11/01/2021

RESUMEN: El declive sufrido por las profesiones clásicas ocasionó que, tras siglos de ejercicio autócrata de la profesión médica —e innumerables privilegios - fuese necesaria una renovación de los valores y principios inspiradores del contrato que les vincula a la sociedad. Ello exigía que, paralelamente, se recuperasen los principios éticos y virtudes que caracterizan a un excelente profesional, reformulándolos para adaptarlos a las nuevas exigencias de la sociedad. En consecuencia, la relación clínica pasó de la estricta intimidad médico-paciente a estar influida por otros sujetos que desvían la atención de los médicos de aquellas metas propias de su profesión. De entre estos sujetos, destaca notoriamente la industria farmacéutica, cuyo poder ha influido en la vocación que une al médico con su profesión, debilitándola y haciendo tambalear los cimientos de la moral propia de estos profesionales..

Palabras clave: conflicto de intereses, medicina, moral, ética, industria farmacéutica, deontología, sesgo, virtud.

ABSTRACT: The decline suffered by classical professions, after centuries of autocracy in the medical profession and uncountable privileges - forced a renewal of the values and inspiring principles of the contract that binds them to society. This required, at the same time, the reformulation of ethical principles and virtues that characterize an excellent professional, in order to adapt them to the new demands of society. Consequently, the clinical relationship went from strict doctor-patient intimacy, to being influenced by other subjects who divert medical attention to the goals of their profession. Out of these subjects, the pharmaceutical industry stands out notably. Their power has influenced the vocation that unites the doctor with his profession, weakening it and shaking the foundations of the morale of said professionals.

Keywords: conflict of interests, medicine, ethics, moral, pharmacy industry, deontology, bias, virtue.

SUMARIO: I. INTRODUCCIÓN - II. ÉTICA DE LA PROFESIÓN MÉDICA - 1. Ética de las profesiones - 2. Ética médica 2.1. Ética y deontología - 2.2 Profesionalismo médico en el contrato médico-sociedad. La búsqueda de la excelencia - III. APROXIMACIÓN A LA NOCIÓN Y CARACTERES DEL CONFLICTO DE INTERESES - IV. Los conflictos de intereses en la relación médico-industria farmacéutica - 1. Marco normativo y deontológico - 2. Ética en la prescripción - 2.1. Libertad de prescripción - 2.2. Principio de justicia en la gestión clínica - 3. Principales situaciones de conflicto 3.1. Formación continuada -3.2. Visitadores médicos - 3.3. Revistas científicas -3.4 . Guías de práctica clínica -4 . Vías para una correcta resolución de las situaciones de conflicto V. CONCLUSIONES - VI. REFERENCIAS BIBLIOGRÁFICAS. 


\section{INTRODUCCIÓN}

Desde su origen como una de las "profesiones clásicas, a la medicina y a quienes la han ejercido se les ha tenido en una altísima consideración moral. De quienes se dedicaban en cuerpo y alma al cuidado de sus iguales no se podía esperar otra cosa que rectitud, por lo que se les colmaba de respeto y prerrogativas.

Con el paso de tiempo, el inmovilismo que había caracterizado al mundo profesional fue cediendo, lo que ocasionó un cambio en la percepción social de las profesiones, considerado por algunos como una autentica "crisis" de las mismas.

Nosotros no entendemos que esta "crisis" haya de entenderse como un declive negativo. Se trata de una disminución del estatus que las profesiones clásicas tenían en la sociedad, de una pérdida de la sacralidad de las mismas, sin que en ningún caso esto implique el declive moral de los profesionales. De hecho, a raíz de este cambio de paradigma se produjo una humanización de las profesiones sanitarias, lo que posibilitó grandes logros como la emancipación de los pacientes y el consecuente reconocimiento de ciertos derechos a estos, acordes con su dignidad como personas.

A este declive del estatus de las profesiones se une la pérdida de valores que ha sufrido nuestra sociedad, y es ahí donde vemos un verdadero problema. Si bien, durante los últimos siglos hemos conquistado un gran número de derechos fundamentales - algunos de ellos profundamente interiorizados por la sociedad-, la configuración geopolítica y económica actual ha desembocado en la primacía de los valores económicos en detrimento de los valores éticos.

Todo ello ha llevado a que surjan un sinfín de situaciones que ponen en claro conflicto de intereses a los profesionales médicos, siendo los más comunes o, quizás, los más notorios, los que derivan de la relación de estos con las empresas farmacéuticas. Se trata de empresas privadas, con un inmenso patrimonio, que han irrumpido en el ámbito de la medicina, utilizando a la misma como un instrumento para la consecución de sus objetivos económicos.

\section{II. ÉTICA DE LA PROFESION MÉDICA}

\section{1. Ética de las profesiones}

La existencia de un deber social y moral que impulsa e inspira la actuación de los profesionales pone de manifiesto la presencia de unos principios mínimos y comunes en la sociedad que han de ser observados por la totalidad de los sujetos, incluidos los profesionales. Nos referimos a una ética cívica o de mínimos que, en consonancia con los valores sociales imperantes en cada momento, adapta el fin último de cada actividad humana a los derechos reconocidos a cada uno de los individuos quienes, a su vez, han de encontrarse reconocidos por la sociedad como "seres dignos del mayor respeto y consideración"1.

\footnotetext{
${ }^{1}$ MARTÍNEZ NAVARRO, E., La Ética profesional como proyecto personal y compromiso de ciudadano. In M. Correa Casanova, \& P. Martínez Becerra, La riqueza ética de las profesiones. RIL Editores. Santiago de Chile. 2010. pp. 23-54.
} 
Esta ética mínima ha influido notablemente en la configuración de una ética de las profesiones, concretamente en lo que respecta a los fines propios de cada profesión ${ }^{2}$. Cada profesión persigue un fin dado históricamente que la define, la identifica y, además, la legitima socialmente ${ }^{3}$. Porque, como afirma Cortina ${ }^{4}$, "cualquier actividad humana cobra su sentido de perseguir un fin que le es propio; y además, cualquier actividad social necesita ser aceptada en la sociedad en la que se desarrolla, necesita estar socialmente legitimada".

Los fines o bienes internos son intrínsecos a la profesión, de esta manera la actividad social que constituye la profesión se convierte en el propio fin de la misma, de una manera similar a la praxis Aristotélica ${ }^{5}$. De la misma manera, dichos bienes vienen dados por la propia profesión, por lo que no pueden ser modificados por los sujetos que vayan a accediendo a ella. Lo que sí ha de hacer cada uno de esos sujetos es mejorarlos, adaptarlos a las nuevas técnicas y a las consideraciones éticas socialmente aceptadas en cada momento ${ }^{6}$.

Junto con los bienes internos encontramos otros, denominados bienes externos (el dinero, el poder y el prestigio son los incentivos principales para la mayor parte de los profesionales), que no aportan legitimación a una profesión. De hecho, son bienes comunes a todas las profesiones e, incluso, a los oficios. Se trata de bienes totalmente lícitos, cuya obtención por los profesionales no tiene por qué suponer ningún problema o merma en la profesionalidad de los mismos, siempre que su consecución quede en un segundo plano.

Por contra, aquel profesional que se centre únicamente en los bienes externos, descuidando la consecución de los bienes internos, sería un corrupto, habría cambiado la propia naturaleza de la profesión, para centrarse en sus propios intereses. La corrupción de los profesionales conlleva la destrucción de la profesión en sí misma, pues la pérdida de la confianza que le es depositada por la sociedad y la correlativa deslegitimación de la misma supone, a nuestro entender, la verdadera crisis de la profesión ${ }^{7}$.

Por último, la excelencia buscada por los profesionales se compone, por un lado, de capacidad y competencia para realizar su labor —aptitudes- y, por otro, de integridad moral y respeto a unos principios éticos - actitudes ${ }^{8}$ - Ser un profesional competente no es sinónimo de serlo excelente, aunque ser competente sea uno de los rasgos que han de estar presentes en todo profesional excelente. Resulta necesario que el sujeto sea un profesional bueno, que cuente con la virtud moral, que haya hecho suyas aquellas actitudes que tienden al pleno servicio a la sociedad, convirtiéndolas en hábitos, de manera que el profesional "salga" de las diferentes situaciones con su integridad intacta? .

2 CORTINA, A., "Universalizar la aristocracia: por una ética de las profesiones”. Claves de razón práctica, núm. 75, 1997, pp. 46-52, 28 de marzo de 2020. Disponible en https://www.uis.edu.co/webUIS/es/mediosComunicacion/revistaSantander/revista1/universalizarAristocracia.pdf

3 GRACIA, D., “Ética profesional y ética institucional: ¿convergencia o conflicto?”, Revista Española de Salud Pública, núm. 80, 2006, pp. 457-467, 10 de abril de 2020. Disponible en http://scielo.isciii.es/scielo.php?script=sci arttext\&pid=S1135-57272006000500004

${ }^{4}$ CORTINA, A., "Universalizar la aristocracia: por una ética de las profesiones”, op. cit., p. 61.

${ }^{5}$ MACINTYRE, A., After virtue: a study in moral theory. Duckworth. Londres. 1985.

${ }^{6}$ CORTINA, A., "Universalizar la aristocracia: por una ética de las profesiones”, op. cit.

${ }^{7}$ CORTINA, A., "Universalizar la aristocracia: por una ética de las profesiones”, op. cit.

${ }^{8}$ MARTÍNEZ NAVARRO, E., La Ética profesional como proyecto personal y compromiso de ciudadano, op. cit.

${ }^{9}$ GRACIA, D., "El recto ejercicio profesional, ¿cuestión personal o institucional?: El caso de la atención al enfermo terminal". Quadern CAPS, núm. 23, 1995, pp. 94-98, 10 de abril de 2020. Disponible en http://www.sidastudi.org/es/registro/2c9391e41fb402cc011fb43c5e2c27a8 


\section{2. Ética médica}

\section{1. Ética y deontología}

Cuando hablamos de ética médica nos referimos a aquella ética aplicada que propugna los principios y valores que han de regir las decisiones de estos profesionales. La ética médica "orienta la conducta del profesional médico hacia el acto médico correcto, y propicia el logro de un estándar ideal y de excelencia de las relaciones que debe establecer con los enfermos"10.

Pese a la existencia de una ética médica común a todos estos profesionales, esta ética aplicada es, a su vez, múltiple. Además, el cumplimiento de dichos principios es una decisión individual de cada sujeto, no existen mecanismos de control coercitivos exógenos que garanticen que un determinado sujeto es fiel a esta ética médica ${ }^{11}$. Al no existir un mecanismo coercitivo concreto, resulta obvio que es necesario un componente intrínseco al sujeto que le lleve a buscar siempre la excelencia pese a no tener que rendir más cuentas que a sí mismo: la vocación.

Por otro lado, el contrato social entre la medicina y la sociedad, así como la dignidad intrínseca a cada uno de los miembros de dicha sociedad, exige el establecimiento de unos mínimos insoslayables. En este contexto, y como complemento a la ética médica, encontramos la deontología médica.

La deontología ha de entenderse como "ciencia del deber" y, como tal, acoge aquellos deberes éticos tradicionales de una profesión concreta. De esta manera, la deontología recoge y sanciona los valores o reglas ad intra de la medicina, el cómo ha de proceder para cumplir el fin interno de la profesión médica, siendo los propios médicos quienes se dotan de dichas normas y velan por el cumplimiento de las mismas ${ }^{12}$.

Con todo, cualquiera de las normas recogidas en los códigos deontológicos se encuentra subordinada a las normas legales imperativas. Esta subordinación no implica, de ninguna de las maneras, una minusvaloración de la deontología, al revés, el potencial de las normas deontológicas es el de estar llamadas a llenar el vacío que dejan aquellas cuestiones no reguladas por el derecho ${ }^{13}$.

Esta relación entre derecho, ética y deontología se completa e integra con la denominada bioética. La Enciclopedia de Bioética ${ }^{14}$, la define como "un estudio sistemático de la conducta humana en el área de las ciencias humanas y de la atención sanitaria en cuanto se examina esta conducta a la luz de los valores y los principios morales". Esta definición es harto ilustrativa de la multidisciplinariedad y transversalidad de esta rama del conocimiento.

\footnotetext{
${ }^{10}$ LIZARASO CAPARÓ, F. y BENAVIDES ZÚÑIGA, A., "Ética Médica”. Horizonte médico, núm.18, 2018, pp. 48,26 de febrero de 2020. Disponible en http://www.scielo.org.pe/scielo.php?script=sci arttext\&pid=S1727$\underline{558 X 2018000400001}$

11 BLANCO MERCADÉ, A., "Vida, ética y deontología médica: aclarando conceptos". EIDON: revista de la fundación de ciencias de la salud, núm. 52, 2019, pp. 23-32, 12 de mayo de 2020. Disponible en https://dialnet.unirioja.es/servlet/articulo?codigo=722502

12 OPPES, M., “¿Cuál es el futuro de la deontología médica?” Medicina y ética: Revista internacional de bioética, deontología y ética médica, núm. 18, 2007, pp. 109-118, 29 de marzo de 2020. Disponible en https://dialnet.unirioja.es/servlet/articulo?codigo=2770553

${ }^{13}$ OPPES, M., “¿Cuál es el futuro de la deontología médica?”, op. cit.

${ }^{14}$ ALTISENT, R., "Ética, bioética y deontología". Revista bioética, núm. 17, 2009, pp. 363-375, 15 de mayo de 2020. Disponible en http://revistabioetica.cfm.org.br/index.php/revista bioetica/article/view/504
} 


\subsection{Profesionalismo médico en el contrato médico-sociedad. La búsqueda de la excelencia}

La realidad social y organizativa de la mayor parte de los países europeos, en la que destaca la existencia de un sistema sanitario público, hace que el primer problema al que tenemos que referirnos es, precisamente, a la institucionalización de la medicina. Se ha convertido a los médicos en una suerte de funcionarios, en trabajadores administrativos que cumplen con su labor de una manera rutinaria, casi mecánica. con la consecuente pérdida de su vocación. En consecuencia, la excelencia moral y el virtuosismo queda en un segundo plano, viéndose abocados a actuar bajo criterios de eficiencia y productividad, conformándose con acatar los protocolos y formalidades que se les impone desde las entidades gestoras ${ }^{15}$.

Además, existen otras cuestiones que han hecho mella en la moral médica, entre ellas, el cambio de la escala de valores que llegó de la mano del nuevo capitalismo; la irrupción de las nuevas tecnologías que cosifican a los pacientes en el marco de relaciones cada vez más impersonales; la incidencia de las empresas farmacéuticas que tientan la moral médica con regalías y notoriedad científica; el cambio en el perfil del paciente, cada vez más exigente.

Como respuesta a estas cuestiones surge el denominado professionalism, de origen anglosajón. Se trata de aquella corriente, dentro de la ética de las profesiones, con la que "se definen los rasgos esenciales del buen hacer de la profesión médica. Abarca aspectos como la reflexión sobre los valores de la profesión, la actuación (praxis) profesional correcta"16.

Borrell-Carrio, Epstein y Pardell Alentà (2006), definen el profesionalismo como "un conjunto de principios y compromisos para mejorar los resultados en salud del paciente, maximizar su autonomía, creando relaciones caracterizadas por la integridad, la práctica ética, la justicia social y el trabajo en equipo" 17 .

La mayoría de los autores comprenden el profesionalismo en el ámbito del contrato social que tiene lugar entre la medicina y la sociedad, pues aquel le otorga a esta los valores y compromisos a observar por los profesionales que, a su vez, sirven de fundamento o base a dicho contrato ${ }^{18}$. Este compromiso es dinámico, cada una de las partes se reconoce recíprocamente unas obligaciones y unos derechos sobre la base de la confianza que se tienen, siendo estos perfectamente renegociables y adaptables a la realidad del momento. Del mismo modo, el profesionalismo no puede entenderse como una realidad estática, sino que los valores y prácticas que lo inspiran han de adaptarse a la realidad social y a las demandas de cada caso concreto $^{19}$.

En 2002 la American Board of Internal Medicine (ABIM), la American College of Physicians-American Society of Internal Medicine (ACP-ASIM) y la European Federation of Internal Medicine, se hicieron eco de las dificultades que atravesaba la profesión médica,

\footnotetext{
${ }^{15}$ CORTINA, A., "Universalizar la aristocracia: por una ética de las profesiones", op. cit.

16 BORRELl-CARRIO, F., EPSTEIN, R. y PARDELL ALENTÀ, H., "Profesionalidad y professionalism: fundamentos, contenidos, praxis y docencia". Medicina Clínica, núm. 127, 2006, pp. 337-342, 20 de marzo de 2020. Disponible en https://www.elsevier.es/es-revista-medicina-clinica-2-articulo-profesionalidad-professionalismfundamentos-contenidos-praxis-docencia-13092322

17 BORRELl-CARRIO, F., EPSTEIN, R. y PARDELL ALENTÀ, H., "Profesionalidad y professionalism: fundamentos, contenidos, praxis y docencia”, op. cit. p. 337.

18 ORIOL, A., "El profesionalismo: asignatura pendiente del sistema educativo médico". EIDON. Revista española de bioética, núm. 33, 2010, pp. 52-57, 30 de marzo de 2020. Disponible en https://www.revistaeidon.es/public/journals/pdfs/2010/33_junio.pdf
}

${ }^{19}$ SÁNCHEZ MARTÍN, M. M., "Profesionalismo". Revista Española de Cirugía Osteoarticular, núm. 47, 2012, pp. 170-180, 10 de marzo de 2020. Disponible en https://dialnet.unirioja.es/servlet/articulo?codigo=4275610 
subrayando esta idea de profesionalismo como base del contrato medicina-sociedad y, a la vez, como solución a tales dificultades ${ }^{20}$.

Por lo que hace a los principios rectores que recoge, encontramos los clásicos principios de la bioética clínica, concretamente: el "principio de la primacía del bienestar del paciente", "principio de la autonomía del paciente" y el "principio de la justicia social". Por otro lado, encontramos diez compromisos de la profesión médica con la sociedad, que se enmarcan dentro de la ética de las virtudes, cuyo cumplimiento precisa la actitud autocrítica y reflexiva de un médico que esté dispuesto a poner al paciente en un primer plano y a abandonar cualquier atisbo de individualismo en las relaciones con el resto de colegas de profesión ${ }^{21}$.

Así, se vuelve a la idea de que no es suficiente con que un profesional sea competente, sino que ha de ser virtuoso, lo que se consigue cumpliendo cada uno de esos compromisos, que han de convertirse en hábitos -en virtudes-, y que se combinan y se complementan con los principios propios de la medicina $^{22}$ (De Santiago, 2014).

\section{APROXIMACIÓN A LA NOCIÓN Y CARACTERES DEL CONFLICTO DE INTERESES}

Un conflicto de intereses es un dilema ético, por lo que se desarrolla en el estricto campo de la moral, el sujeto ha de plantearse cuál es la opción optima decidiendo tras el correspondiente juicio interno inspirado por unas normas y principios éticos adecuados ${ }^{23}$.

El conflicto de intereses, como cualquier dilema ético, no implica tomar una decisión entre una opción buena y otra mala. Se trata de una elección del tipo "correcto vs. correcto" para llegar a la solución óptima, lo que supone que la decisión va a ser mucho más complicada que si cualquiera de las opciones que se nos presentan fuera "mala" y, por ende, fácilmente descartable ${ }^{24}$. De esta manera, podríamos definir el conflicto de intereses de la siguiente manera:

Es una figura moral que aparece en la conducta de quien tiene un deber u obligación (interés primario) que choca con un interés de carácter personal (interés secundario), que puede distorsionar el juicio profesional de un modo no razonable o inaceptable, haciendo temer que la justicia sea lesionada ${ }^{25}$.

De la noción de conflicto de intereses dada anteriormente tenemos que hacer hincapié en la expresión "puede distorsionar", pues pone de manifiesto su naturaleza potencial. "Se puede decir que un conflicto de interés es una inducción o tentación que debe diferenciarse de

\footnotetext{
${ }^{20}$ ABIM Foundation, ACP-ASIM Foundation, \& European Federation of Internal Medicine. "Profesionalidad médica en el nuevo milenio: un fuero médico". Revista Clínica Española, núm. 202, 2002, pp. 449-452, 3 de abril de 2020. Disponible en https://www.revclinesp.es/es-profesionalidad-medica-el-nuevo-milenio-articulo-13035644

${ }^{21}$ DE SANTIAGO, M., "Las Virtudes en Bioética Clínica”. Cuadernos de Bioética, núm. 1, 2014, pp. 75-91, 15 de marzo de 2020. Disponible en https://libros-revistas-derecho.vlex.es/vid/virtudes-bioa-tica-cla-nica-510964678

22 DE SANTIAGO, M., "Las Virtudes en Bioética Clínica", op. cit.

${ }^{23}$ GÓMEZ CÓRDOBA, A. I., LATORRE SANTOS, C. y NEL CARREÑO, J., "Dilemas éticos en las relaciones entre la industria farmacéutica y los profesionales de la salud". Persona y bioética, núm. 11, 2007, pp. 23-38, 5 de marzo de 2020. Disponible en https://dialnet.unirioja.es/servlet/articulo?codigo=2361049

${ }^{24}$ KIDDER, R. M., How Good People Make Tough Choices: Resolving the Dilemmas of Ethical Living. William Morrow. Nueva York. 1995.

${ }^{25}$ ALTISENT, R., DELGADO MARROQUÍN, M. T. y ASTIER PEÑA, M. P., "Conflictos de interés en la profesión médica". Atención Primaria, núm. 51, 2019, pp. 506-511, 28 de febrero de 2020. Disponible en https://www.sciencedirect.com/science/article/pii/S0212656719303634
} 
su aceptación" 26 . Ergo, la existencia de un conflicto de intereses en sí es independiente de que se ceda o no ante el mismo. La existencia de más de un interés no es un problema ético, incluso hay autores que afirman que el conflicto de interés puede llegar a ser positivo si sirve para potenciar la consecución del interés primario ${ }^{27}$.

Una de las principales problemáticas que se presentan en relación con los conflictos de intereses es su carácter interno, suceden en el ámbito de la intimidad personal del sujeto. En principio, solo la persona que se encuentra ante un conflicto de intereses es quien puede tener verdadera constancia de la existencia del mismo. El resto de personas podemos intuirlo ante ciertos indicios y, en el peor de los casos, ver sus efectos.

Simultáneamente, aquellas personas que se encuentran ante un conflicto de interés tienden a lo que Genta-Mesa y Flórez (2019), basándose en la psicología social, denominan "punto ciego al propio sesgo" (pág. 304). Nuestra mente intenta evitar la incomodidad producida por la existencia del conflicto de intereses .

Para ello, tendemos a utilizar mecanismos de negación que implican actitudes como negar que determinadas situaciones puedan llegar a suponer un conflicto de intereses o desacreditarlos con argumentos que hacen referencia a lo ecuménico de los mismos. En segundo lugar, tendemos a racionalizar el problema, afirmando que nuestra imparcialidad es insoslayable y haciendo hincapié en los beneficios que se derivan de la situación con potencial para crear un conflicto $^{28}$.

Sah y Loewenstein, tras un estudio sobre los sesgos conscientes e inconscientes, plantearon que, "las racionalizaciones rechazadas en un nivel consciente pueden ayudarnos a racionalizar inconscientemente el comportamiento cuestionable". Esto implica que, aunque el sujeto inicialmente fuera perfectamente consciente de que determinada situación puede poner en conflicto sus intereses - lo que implica que inconscientemente no ha utilizado ningún mecanismo de negación o racionalización del mismo - se le pueden inducir inconscientemente dichas racionalizaciones ${ }^{29}$.

La resolución de los conflictos de intereses por aquellos que pudieran verse afectados varía en función de los valores concretos que se encuentren en conflicto y la manera en que dicho conflicto ha sido inducido. No obstante, las características hasta ahora expuestas permiten afirmar que, en cualquiera de los casos, el primer paso hacia su resolución es tomar conciencia de los mismos y de las situaciones que pudieran causarlos, lo que permitirá al sujeto evitar aquellas susceptibles de desembocar en un conflicto de interés. Si un sujeto se encuentra en una situación de conflicto de sus intereses que no ha podido evitar, procede enfrentarlo desde un juicio inspirado en la prudencia ${ }^{30}$.

${ }^{26}$ ALTISENT, R., DELGADO MARROQUíN, M. T. y ASTIER PEÑA, M. P., "Conflictos de interés en la profesión médica", op. cit. p. 509.

${ }^{27}$ CAROT, G., VALLÈS, X., BONMATÍ, M., GISPERT, B., TARRUELLA, M. D. y ROVIRA, J., "El conflicto de intereses en los profesionales de la salud". Bioètica \& debat: Tribuna abierta del Institut Borja de Bioètica, núm. 81, 2017, pp. 3-25, 20 de mayo de 2020. Disponible en https://dialnet.unirioja.es/servlet/articulo?codigo=6260187

${ }^{28}$ SAH, S. y FUGH-BERMAN, D., "Physicians under the Influence: Social Psychology and Industry Marketing Strategies". Journal of Law, Medicine and Ethics, núm. 14, 2013, pp. 665-672, 2 de abril de 2020. Disponible en https://papers.ssrn.com/sol3/papers.cfm?abstract_id=2286433

${ }^{29}$ SAH, S. y FUGH-BERMAN, D., "Physicians under the Influence: Social Psychology and Industry Marketing Strategies", op. cit.

30 ARGANDOÑA, A., "Conflicto de intereses: el punto de vista ético". In C. d. Negocios (Ed.), XII Conferencia anual de Ética, Economía y Dirección, 2004, 20 de mayo de 2020. Disponible en https://www.ieseinsight.com/fichaMaterial.aspx?pk=1870\&idi=1\&origen=1\&idioma=1 


\section{LOS CONFLICTOS DE INTERESES EN LA RELACIÓN MÉDICO-INDUSTRIA FARMACÉUTICA}

En el ámbito de la medicina, nos encontramos ante un genuino conflicto de intereses "cuando, más allá de sus obligaciones de proteger y promover los intereses de los pacientes, los médicos tienen un interés personal, frecuentemente financiero, que se opone a la fidelidad o lealtad a sus pacientes" ${ }^{31}$. Es importante tener en cuenta que, la configuración del bien primario propio de la medicina como un derecho fundamental y la financiación pública del sistema de salud, ocasionan que "la línea que define la transgresión moral, ética o incluso la mala praxis [sea] mucho más sensible" ${ }^{32}$.

Las situaciones de conflicto de intereses a las que un médico puede enfrentarse son de muy diversa índole, algunas surgen de la organización de la medicina en torno a un sistema de salud público, otras de las aspiraciones personales y académicas y, por último, encontramos conflictos de intereses de tipo económico. Estos últimos derivan, fundamentalmente, de las relaciones de los médicos con la industria, en su mayoría la industria farmacéutica, aunque también pueden surgir a raíz de los negocios que lleguen a tener los propios médicos.

No pretendemos demonizar a las empresas farmacéuticas, somos conscientes de los múltiples beneficios que estas aportan a la sociedad. No obstante, resulta bastante evidente que las farmacéuticas son empresas y, aunque su actividad se dirija a la obtención de medicamentos capaces de sanar a las personas, ello es solo un medio para conseguir su fin de lucro.

La empresa como entidad busca la excelencia en el beneficio económico, pues solo con un alto índice de beneficios puede mantener su competitividad y solo así puede garantizar prestar con una calidad mínima la actividad que constituye su objeto social.

El hecho de que la actividad de las empresas farmacéuticas, como tales empresas, se dirija a aumentar sus beneficios económicos, en puridad no debería presentar mayores problemas. El problema viene cuando otros sujetos, como son los médicos, son utilizados como medios de obtención de tales beneficios.

Los mecanismos utilizados son de diferente tipo y alcance, siendo el vínculo común de todos ellos, el que buscan despertar en los sujetos una respuesta emocional no consciente. Esta matización es importante pues, si la transgresión en la consecución del bien primario es consciente, consideramos que estaríamos ante un supuesto de corrupción, no de yuxtaposición de intereses.

\section{Marco normativo y deontológico}

La repercusión de las atenciones de la industria farmacéutica hacia los médicos ha sido tal y tan manifiesta que no solo la ética o la deontología han tratado esta cuestión, también el derecho ha entrado en la cuestión señalando aquellos mínimos, cuyo incumplimiento implicaría un atropello de los principios que garantizan la convivencia social.

No obstante, la regulación en este tema es especialmente parca, de hecho, solo se consideran contrarias a derecho aquellas atenciones cuyo valor no sea "insignificante", en tanto

\footnotetext{
${ }^{31}$ BEAUCHAMP, T. y CHILDRESS, J. F., Principles of biomedical ethics, Oxford University Press, Nueva York, 1983, p. 318.

32 CAROT, G., VALLÈS, X., BONMATÍ, M., GISPERT, B., TARRUELLA, M. D. y ROVIRA, J., “El conflicto de intereses en los profesionales de la salud", op. cit, p. 4.
} 
en cuanto no sean útiles para el desarrollo de su profesión. A mayor abundamiento, todas las atenciones de la industria hacia los médicos cuyo valor se considere insignificante o, no siendo de ínfimo valor, presenten alguna utilidad para el desempeño de la profesión serán, al menos desde el punto de vista jurídico, permitidas ${ }^{33}$.

Hubiera sido aconsejable que el legislador diera criterios objetivos que permitan determinar qué ha de entenderse por "valor insignificante" o "relevancia para la práctica de la medicina", cuestión que creemos sencilla, al menos, en lo que se refiere al valor de dichas dádivas. La indeterminación jurídica nunca es positiva pero, ante un adversario económicamente fuerte y con gran influencia, se presenta como un camino abierto para la consolidación e inmunidad de estas prácticas.

Dejando fuera aquellas conductas que puedan encuadrarse dentro de tipos delictivos como el cohecho, las normas encargadas de reglamentar esta cuestión son el Real Decreto 1416/1994, de 25 de junio, por el que se regula la publicidad de los medicamentos de uso humano y el Real Decreto Legislativo 1/2015, de 24 de julio, por el que se aprueba el texto refundido de la Ley de garantías y uso racional de los medicamentos y productos sanitarios.

A grandes rasgos, esta última norma se ocupa de establecer el régimen de incompatibilidades de aquellos que tengan "cualquier clase de intereses económicos directos derivados de la fabricación, elaboración, distribución y comercialización de los medicamentos y productos sanitarios"; así como de sancionar como infracciones administrativas graves algunas de estas conductas. Concretamente, se sanciona tanto la aceptación por los sanitarios, como el ofrecimiento, directo o indirecto, a estos sujetos o a sus parientes y convivientes, de "incentivos, bonificaciones, descuentos prohibidos, primas u obsequios, efectuados por quien tenga intereses directos o indirectos en la producción, fabricación y comercialización de medicamentos".

Centrándonos en el Real Decreto 1416/1994, es la Sección 5. "O "Otros medios de publicidad", del Capítulo III "Publicidad dirigida a las personas facultadas para prescribir o dispensar medicamentos", la que se encarga de regular estas dádivas. El hecho de que dichas cuestiones se incardinen en un capítulo dedicado a la publicidad muestra que, sin lugar a duda, todas estas actuaciones de la Industria tienen un fin meramente publicitario, despejando toda clase de duda en torno a la idea de que estas atenciones responden a un afán desinteresado de la Industria en colmar de atenciones al médico o en la promoción y difusión del saber científico.

Empezando por el artículo 17, este prohíbe aquellas prácticas de promoción de los productos farmacéuticos consistentes en ofrecer u otorgar ventajas, pecuniarias o en especie, a las personas capacitadas para prescribir medicamentos, salvo que las mismas tengan un valor insignificante y no guarden una relación directa con el ejercicio de la medicina. Es, en este último inciso, donde encuentran salvaguarda la mayoría de los obsequios de ínfimo valor que las farmacéuticas hacen a los profesionales médicos, como bolígrafos, calendarios, agendas etc.

A continuación, el artículo 18 excluye de la prohibición antes vista a aquellas manifestaciones propias de la hospitalidad, de carácter exclusivamente profesional y científico. Además, el inciso segundo del mismo precepto establece la posibilidad de que las empresas farmacéuticas promocionen la formación continuada de los médicos, permitiendo que estas financien la asistencia de los mismos a congresos, ponencias y otros simposios, siempre que estos tengan un carácter científico.

\footnotetext{
33 GILI PASCUAL, A., "Los incentivos en el ámbito sanitario ante el derecho penal". Cuadernos de Política Criminal, núm. 122, 2017, pp. 47-87, 19 de abril de 2020. Disponible en https://app.vlex.com/\#search/jurisdiction:ES/LOS+INCENTIVOS+EN+EL+\%C3\%81MBITO+SANITARIO+ANTE +EL+DERECHO+PENAL/WW/vid/699933281
} 
Por supuesto, la industria farmacéutica ha aprovechado estas licencias para financiar vacaciones pagadas en destinos idílicos y hoteles lujosos a los profesionales médicos. Estos viajes se camuflan bajo la imagen de congresos u otras citas de índole científica en los que, en los mejores casos, el contenido científico o académico de los mismos supone una pequeña parte de la duración total de dichos viajes

Por lo que hace al Código de Deontología Médica ${ }^{34}$, aunque es el primero de los Códigos Deontológicos de Medicina españoles que entra a considerar este tipo de cuestiones de una manera contundente, tampoco se muestra todo lo detallista que debería al tratar las mismas. Las cuestiones más relevantes de esta regulación se encuentran, casi en su totalidad, en los artículos 23 y 66 del mismo.

Así, en el apartado dos del artículo 23, tras resaltar la importancia de la colaboración de los médicos con la industria farmacéutica en materia de medicamentos, señala que "es contrario a la Deontología Médica solicitar o aceptar contraprestaciones a cambio de prescribir un medicamento o utilizar un producto sanitario". A continuación, en el apartado 7, se recoge la obligación de los médicos de ser transparentes con respecto a la financiación que reciban de entidades con ánimo de lucro para el desarrollo de actividades científicas o de formación. Apuntándose in fine a la necesidad de que los médicos organizadores de dichas actividades garanticen la independencia de los contenidos de las mismas. Por lo que hace a los apartados 8 y 9 , estos se ocupan de recoger las obligaciones de los médicos que participan en investigaciones o estudios patrocinados por una empresa farmacéutica.

Por último, el numeral 66 señala que "el médico no percibirá comisión alguna por sus prescripciones ni por los materiales empleados en la atención de los pacientes ni podrá exigir o aceptar retribuciones de intermediarios".

Otro documento al que debemos referirnos es el Código de Buenas Prácticas de la Industria Farmacéutica ${ }^{35}$, creado por Farmaindustria (Asociación Nacional Empresarial de la Industria Farmacéutica establecida en España). Este documento se presenta como la materialización del compromiso de autorregulación adoptado por las empresas que forman parte, con la finalidad de, según vemos en su página web, establecer "criterios y normas de conducta que garanticen la confianza y credibilidad en la promoción de los medicamentos y las interrelaciones de la industria farmacéutica" ${ }^{\text {"36 }}$.

Este Código, centra su actuación en tres ámbitos concretos: la promoción de medicamentos de prescripción, la interrelación con profesionales sanitarios y con las organizaciones sanitarias y la interrelación con las organizaciones de pacientes.

De entre sus normas, merece la pena destacar aquellas que se dirigen a regular la relación de la Industria con los profesionales y organizaciones sanitarias (Capítulo II), más concretamente los artículos 10, 11 y 12. En esta línea, el artículo 10, establece las garantías para preservar la independencia de estos operadores y organizaciones. Así, en su apartado primero "se prohíbe el ofrecimiento o la entrega directa o indirecta a Profesionales Sanitarios de cualquier tipo de incentivo, prima u obsequio (en efectivo o en especie)", quedando exceptuados los utensilios de uso profesional y los artículos de escritorio no relacionados directamente con un medicamento, y cuyo valor en el mercado no supere los 10 euros.

\footnotetext{
34 “Código de Deontología Médica”, Organización Médica Colegial de España, 2011, 27 de febrero de 2020. Disponible en: https://www.cgcom.es/codigo_deontologico/files/assets/basic-html/page-2.html

35 "Código de Buenas Prácticas de la Industria Farmacéutica", España, 2016, 1 de mayo de 2020. Disponible en https://www.codigofarmaindustria.org/servlet/sarfi/codigo/codigo.html

36 "Código de Buenas Prácticas de la Industria Farmacéutica", op. cit.
} 
Así mismo, el apartado segundo permite la entrega de materiales formativos o informativos a los profesionales sanitarios, siempre que los mismos sean de escaso valor (hasta 60 euros), estén directamente relacionados con el ejercicio de su profesión y beneficien, de manera directa, a los pacientes. Por lo que hace a los efectos de utilidad médica dirigidos a la formación, se establece el mismo límite de valor que en el caso de los materiales, añadiéndose el requisito de que "no alteren la práctica profesional habitual de su destinatario".

A continuación, el articulo 11 regula de manera detallada y pormenorizada aquellos eventos organizados o patrocinados por cualquiera de las compañías adscritas, o bajo el control de alguna de ellas, cuando todos los participantes sean profesionales sanitarios o cualquier otro profesional con capacidad para prescribir.

Veamos aquellas cuestiones más llamativas de dicho precepto: se prohíbe la organización o colaboración de los laboratorios farmacéuticos en eventos en los que se lleven a cabo actividades de entretenimiento o de carácter lúdico, lo que no excluye cócteles, almuerzos de trabajo y cenas de gala habituales en los eventos, siempre que sean razonables y moderadas, fijándose una cantidad máxima de 60 euros por comensal para estas comidas o almuerzos. En caso de que el evento se celebre fuera de nuestras fronteras, en esta materia se aplicarán las normas propias de aquel lugar; la hospitalidad en dicho eventos ha de ser razonable, no pudiendo exceder su coste de aquel que "los destinatarios estarían normalmente dispuestos a pagar en las mismas circunstancias", sin que pueda incluir a personas diferentes de los profesionales; se acepta el pago de honorarios y gastos a los moderadores y ponentes, pero no se puede ofrecer dinero a los asistentes como forma de compensar el tiempo invertido y, dichos eventos, solo podrán celebrarse en el extranjero si la mayor parte de los participantes proceden del extranjero o, porque esté en el extranjero un recurso o experto relevante (en este caso deberá contarse con la previa autorización de la Unidad de Supervisión Deontológica).

Por lo que hace al artículo 12, en él se recogen algunas pautas de actuación para los visitadores médicos, concretamente, la necesidad de contar con un adecuado conocimiento científico, la prohibición de ofrecer incentivo o pago alguno por la entrevista y la necesidad de causar el mínimo inconveniente por la frecuencia, momento y duración de las visitas.

No obstante, coincidimos con Gili Pascual ${ }^{37}$ en que, pese a las buenas intenciones con las que este se presentó y el hecho de que disponga mecanismos concretos de control y corrección de aquellas actuaciones, la realidad muestra que su eficacia es relativa, pues deja espacio a muchas actuaciones poco éticas y a mecanismos para sortear sus normas — como veremos a continuación-, a lo que ha de sumarse el hecho de que no todas las compañías farmacéuticas con intereses comerciales en nuestro país se han adherido al mismo.

\section{2. Ética de la prescripción}

Toda la actuación que la industria farmacéutica proyecta sobre los médicos se dirige, ya sea directa o indirectamente, a conseguir que estos se decanten por prescribir los productos que aquella comercializa, de manera que los beneficios de estas empresas asciendan hasta el punto de que la inversión les resulte rentable. Por ello, hemos de analizar cómo se lleva a cabo el concreto acto médico de la prescripción y cuáles son los principios éticos que han de ser tomados en consideración para que esta actuación resulte éticamente idónea.

\subsection{Libertad de prescripción}

${ }^{37}$ GILI PASCUAL, A., "Los incentivos en el ámbito sanitario ante el derecho penal”, op. cit. 
La Ley 44/2003, de 21 de noviembre, de ordenación de las profesiones sanitarias remarca, a lo largo de todo su articulado, la autonomía de los médicos, reconociendo expresamente que "el ejercicio de las profesiones sanitarias se llevará a cabo con plena autonomía técnica y científica, sin más limitaciones que las establecidas en esta ley y por los demás principios y valores contenidos en el ordenamiento jurídico y deontológico".

Como manifestación de esta autonomía en el ejercicio de la medicina encontramos, y a nuestro parecer así ha de seguir siendo, la libertad de prescripción, reconocida expresamente en el artículo 23, apartado primero, del Código de Deontología Médica, según el cual, "el médico debe disponer de libertad de prescripción, respetando la evidencia científica y las indicaciones autorizadas, que le permita actuar con independencia y garantía de calidad" ${ }^{\prime 3}$.

En base a aquello, la libertad de prescripción se puede definir, desde una perspectiva técnica, como la capacidad del médico de elegir, de entre los diferentes tratamientos disponibles de acuerdo con el estado de la ciencia, aquel más idóneo y eficaz, atendiendo a la clínica que presente el paciente tras el correspondiente diagnóstico basado en la evidencia ${ }^{39}$.

Por su puesto, esta libertad no es absoluta, los profesionales han de tener muy presente que "la prescripción es un acto clínico complejo que además de conocimientos técnicos, requiere habilidades de escucha y comunicación y una reflexión sobre los valores que están implícitos en dicho acto y las actitudes con que lo afronta[n]mos" ${ }^{40}$. Volvemos así al binomio aptitud y actitud, de manera que la prescripción buena ha de conseguir el equilibrio entre la autonomía y el saber científico del médico y los derechos de los pacientes.

La ética de la prescripción se nutre de los clásicos principios de la bioética clínica —que se ven modulados por una aplicación específica de los mismos- y reajusta los compromisos a los que el médico se vincula por medio del contrato social a las particularidades que presenta el acto de la prescripción, de manera que este no sea enteramente técnico o pautado.

Los principios de beneficencia y no maleficencia se presentan como dos aristas de una misma realidad. Así, el principio de beneficencia implicaría prescribir el mejor y más adecuado tratamiento, de aquellos disponibles. El mejor y más adecuado, por lo tanto, excluye aquel en que la relación riesgo-beneficio se presenta desmedida, sometiendo al paciente a peligros innecesarios, lo que nos lleva al principio de no maleficencia.

Una prescripción beneficente y, por ende, no maleficente, se adecuaría a la lex artis y al conocimiento científico, ha de ser técnicamente adecuada para serlo éticamente ${ }^{41}$.

No obstante, en toda prescripción médica hay un atisbo de incertidumbre sobre los beneficios o riesgos que puedan devenir. Por un lado, muchos de los estudios sobre la incidencia de ciertos medicamentos, llegan a los médicos de manera sesgada; por otro, en cada paciente se dan unas variantes subjetivas únicas, que dificultan la extrapolación de los datos a un caso concreto $^{42}$.

\footnotetext{
38 “Código de Deontología Médica”, op. cit. p. 21.

39 HIDALGO CARBAllal, A. y GONZÁLEZ PERNÍA, J., "Ética de la prescripción. Ciencia y conciencia. Primera parte". SEMERGEN: revista española de medicina de familia, núm. 3, 2009, pp. 156-160.

${ }^{40}$ MOYA BERNAL, A., "Ética de la prescripción”. Información terapéutica del Sistema Nacional de Salud, núm. 35, 2011, pp. 57-63.

${ }^{41}$ MARTÍN MORENO, S., "Ética de la prescripción. Conflictos del médico con el paciente, la entidad gestora y la industria farmacéutica". Atención Primaria, núm. 116, 2001, pp. 299-306.
}

${ }^{42}$ MOYA BERNAL, A., "Ética de la prescripción”, op. cit. 
Como solución, Moya Bernal habla de la virtud de la prudencia que, según el autor, permite a los prescriptores "el manejo razonable de la incertidumbre" y "saber tomar decisiones en situaciones inciertas". La phronesis ha de ser entendida como una virtud intelectiva y volitiva, de manera que permita una reflexión crítica desde la ciencia y la ética, aunando estos conocimientos de manera que el médico pueda tomar en consideración todas las opciones, decidiéndose por la más adecuada y responsabilizándose de su decisión ${ }^{43}$.

A continuación, encontramos el principio de respeto a la autonomía del paciente, que implica que toda decisión sobre cualquier tratamiento debe tomarse de una manera consensuada entre el médico y el paciente. El paciente debe participar en el procedimiento deliberativo y prestar su consentimiento a la conclusión a que se llegue tras el mismo.

La correcta aplicación de este principio exige un médico comunicativo, capaz de escuchar a sus pacientes, los cuales deben ser considerados por el profesional como interlocutores válidos. Evidentemente el respeto a la autonomía del paciente no implica una tolerancia excesiva ante las peticiones del paciente.

Por último, hemos de hacer referencia al principio de justicia y que, en el campo concreto de la prescripción, nos exige un reparto equitativo y racional de los recursos farmacológicos limitados ${ }^{44}$.

\subsection{Principio de justicia en la gestión clínica}

La actual aplicación y modulación del principio de justicia en la prescripción ha de ponerse en relación con el denominado Managed Care o gestión clínica,

El Estado del Bienestar, como materialización lógica del Estado Social de Derecho, implica que es el Estado el que ha de asegurar la realización del derecho a la salud. En un inicio, esta concepción no presentó mayores problemas, no obstante, a finales del siglo XX, tras la crisis económica de 1973, la proliferación de costosas tecnologías en medicina, y el aumento de la esperanza de vida, hicieron necesario replantear el modelo económico de los recursos sanitarios. Cuestión todavía más agravada con la reciente crisis económica vivida desde la primera década del presente siglo $\mathrm{XXI}^{45}$.

En este contexto de crisis, las medidas de control del gasto se multiplicaron, dando entrada a la "economía de la medicina" y adoptándose medidas de gestión de la medicina pública en términos similares a las utilizadas para la gestión de las empresas privadas ${ }^{46}$. Se comenzó a dar una gran importancia a la relación eficacia-coste de los recursos sanitarios, exigiendo a los médicos un control del gasto.

Vemos que el médico se ha convertido en el distribuidor de los recursos públicos, es quien decide cómo se distribuyen los limitados recursos con los que cuenta nuestro sistema de salud, con la consiguiente responsabilidad hacia la colectividad que ello implica ${ }^{47} . Y$ es, precisamente, en el marco de dicha responsabilidad hacia la colectividad, donde ha de

\footnotetext{
${ }^{43}$ MORENO VILLARES, J. M., "Prudencia, virtud indispensable”. Cuadernos de Bioética, núm. 25, 2014, pp. 105110 .

${ }^{44}$ MOYA BERNAL, A., "Ética de la prescripción”, op. cit.

${ }^{45}$ ORTIZ POMMIER, A., “Gestión clínica y conflicto de intereses”. Acta bioethica, núm. 15, 2009, pp. 157-164.

46 COUCEIRO VIDAL, M. A., "Los niveles de la justicia sanitaria y la distribución de los recursos". Anales del Sistema Sanitario de Navarra, núm. 29, 2006, pp. 61-74.

${ }^{47}$ ORTIZ POMMIER, A., "Gestión clínica y conflicto de intereses”, op. cit.
} 
encuadrarse la necesidad de que el acto de la prescripción se ajuste, además de a los conocimientos científicos, a criterios de eficiencia.

Por lo tanto, la eficiencia en que se traduce la relación coste-eficacia ha de ser observada por los facultativos como una exigencia más del principio de justicia, buscando siempre el beneficio del paciente y, además, de un mayor número de pacientes. No obstante, al igual que resulta poco ética la prescripción de medicamentos con una mala relación eficaciaprecio, tampoco es ético absolutizar la eficiencia ${ }^{48}$.

No podemos considerar la eficiencia, por sí sola, como un objetivo de nuestro sistema de salud ${ }^{49}$, la eficiencia ha de considerarse un valor instrumental, un simple medio para lograr la equidad y, con ella, la justicia como un valor intrínseco ${ }^{50}$.

Que el médico deba ser consciente de la realidad económica del sistema del que forma parte y de la necesidad de una justicia distributiva y equitativa que garantice el acceso a los recursos del sistema de salud a todo aquel que lo necesite, es parte de una prescripción ética y, en ningún caso debe implicar que el médico se convierta en una suerte de economista o gestor del gasto ${ }^{51}$. Son los gestores quienes han de elaborar los planes de gestión de manera adecuada, tomando medidas como incluir en el vademécum de la sanidad pública solo aquellos medicamentos cuya relación efectividad-coste resulte positiva ${ }^{52}$.

Forzar a los prescriptores para que prioricen el gasto económico frente a otros criterios puede resultar en un conflicto de índole moral para el médico, que se verá abocado a actuar en contra de sus propios valores.

\section{Principales situaciones de conflicto}

Las técnicas de promoción que las empresas farmacéuticas utilizan para influir en las decisiones prescriptoras de los médicos pueden materializarse de maneras muy diversas.

Parte de esta promoción se ejerce directamente sobre los propios facultativos, pero también encontramos formas indirectas que, aunque en última instancia se dirigen a influir en la tendencia de prescripción y el uso de fármacos que viene haciendo un facultativo, no se proyectan inicialmente sobre el médico, sino sobre otros sujetos (por ejemplo, investigadores, editoriales y organizaciones científicas).

\subsection{Formación continuada}

La excelencia en la práctica de la medicina y, en general, de cualquier profesión, implica un equilibrio entre saber científico y valores éticos, por lo que, mantener dichas aptitudes continuamente actualizadas es uno de los compromisos del médico con la sociedad.

\footnotetext{
${ }^{48}$ MOYA BERNAL, A., "Ética de la prescripción”, op. cit.

${ }^{49}$ MOYA BERNAL, A., "Ética de la prescripción”, op. cit, p. 59.

${ }^{50}$ GRACIA, D., "La ética en las instituciones sanitarias: entre la colaboración y el conflicto", La ética en las instituciones sanitarias: entre la lógica asistencial y la lógica gerencial, Fundación Víctor Grifols i Lucas, Barcelona, 2012, pp. 13-21.

${ }^{51}$ MARTÍN MORENO, S., "Ética de la prescripción. Conflictos del médico con el paciente, la entidad gestora y la industria farmacéutica", op. cit.

${ }^{52}$ MOYA BERNAL, A., "Ética de la prescripción”, op. cit.
} 
En relación con esta cuestión, el Código de Deontología Médica señala, en varias ocasiones, la obligación que tienen los médicos de mantenerse actualizados e informados en lo que respecta a las técnicas e instrumentos propios de su ciencia. Pese a que el propio Código señala que han de ser las instituciones públicas quien pongan a disposición de los profesionales médicos dicha formación continuada, la insuficiencia de medios de nuestras instituciones ha desembocado en que sean las compañías farmacéuticas quienes les provean de tal formación. De hecho, por lo que hace a la asistencia a seminarios, simposios o conferencias, parece que el propio legislador ha asumido la existencia de esta relación, limitándose a establecer en el Real Decreto legislativo 1/2015, ciertas medidas para garantizar que dichos eventos formativos se celebren con las mayores garantías de transparencia.

De lo hasta aquí planteado resulta que la relación entre los profesionales médicos y la Industria no plantea mayor problema ético, de hecho, se podría decir que se presenta como beneficiosa, en tanto en cuanto, permite a los médicos saber cuáles son las diferentes novedades farmacológicas del mercado.

Sin embargo, la industria farmacéutica prácticamente ha monopolizado la formación de los facultativos, ampliando su presencia, directa o indirectamente, a todos los frentes en los que la misma se lleva a efecto. Además, dicha intervención no se limita a la divulgación de la información técnica relativa a sus nuevos productos y a facilitar el acceso a medios formativos a los médicos, sino que, toda ella, lleva consigo una implícita campaña publicitaria.

Esto no solo implica que la formación de los médicos no es tal, pues se muestra incompleta y sesgada, desembocando en la pérdida del rigor científico y en el consecuente perjuicio para el paciente. Sino que, además, afecta de manera flagrante a la independencia del médico quien, inevitablemente, tendrá un sentimiento de deuda con su mecenas.

Se trata de eventos con una supuesta finalidad de divulgación del conocimiento científico, muchas veces organizados directamente por la Industria y, otras, organizados por asociaciones científicas pero con el respaldo económico de aquella. En los peores casos, dichos eventos son, en esencia, vacaciones pagadas a un destino de moda, sin que exista un verdadero contenido científico, o siendo este ínfimo ${ }^{53}$.

La mayor parte de las personas que imparten este tipo de formaciones no están totalmente desvinculadas del ámbito de la empresa promotora pero, incluso, en aquellos casos en los que los ponentes no tienen ningún tipo de relación con la Industria, el simple hecho de que esta sea la encargada de promocionar el evento ya implica una asociación entre lo que se exponga por aquel y esta ${ }^{54}$.

Dentro de aquellos ponentes que tienen una relación con la Industria, merecen especial atención los denominados "líderes de opinión". Estos suelen tener un vínculo con la empresa organizadora anterior al evento, y además, reciben una remuneración económica directa por parte de dicha empresa en concepto de dicha ponencia. Al tratarse de una relación puramente mercantil, si estos expertos se apartan de dicha línea, o no muestran de manera adecuada los beneficios de un producto, la empresa no vuelve a contratarlo, lo que al final permite a las farmacéuticas crear una cartera de oradores realmente fieles a sus productos ${ }^{55}$.

\footnotetext{
${ }^{53}$ BUFFO SEQUEIRA, I., ARROYO CASTELÁN, E., HALABE CHEREM, J. y MONROY SAINT MARTIN, M., "El médico y la relación con la industria farmacéutica". Revista CONAMED, núm. 17, 2012, pp. 182-186.

${ }^{54}$ MARTÍN MORENO, S., "Ética de la prescripción. Conflictos del médico con el paciente, la entidad gestora y la industria farmacéutica", op. cit.

${ }^{55}$ BUFFO SEQUEIRA, I., ARROYO CASTELÁN, E., HALABE CHEREM, J. y MONROY SAINT MARTIN, M., "El médico y la relación con la industria farmacéutica", op. cit.
} 
Paralelamente, la invitación de la industria farmacéutica a dichos eventos no acaba en financiar la simple asistencia al evento, sino que comprende lo denominado como "hospitalidad". La hospitalidad incluye todas aquellas atenciones que puede recibir el médico mientras dure la actividad, lo que abarca obsequios promocionales, cócteles, almuerzos o cenas de gala, gastos de transporte y, de ser necesario, el alojamiento durante los días que dure el evento.

Es cierto que, como se apuntó supra, estas cuestiones se han tratado y regulado por el Código de Buenas Prácticas de la Industria Farmacéutica con el fin de desalentar su continuidad. Sin embargo, aun ajustándose estrictamente a las disposiciones del código, resulta que esta hospitalidad es capaz de comprometer la independencia del médico. Recordemos que, por ejemplo, las cenas de gala no están sujetas a ningún tipo de límite y, en el caso de los almuerzos y las comidas, se establece un límite bastante elevado de 60 euros por comensal.

Por mucho que el profesional crea que, el recibir financiación para su formación responde únicamente a un afán por mejorar el sistema sanitario y las aptitudes de quienes lo componen, el sentimiento de deuda que se genera en él es inevitable y compromete, sin lugar a duda, su autonomía y su capacidad de ser crítico ante aquellas informaciones que se le suministren. Recordemos que, "la imparcialidad en la formación es imprescindible a la hora de garantizar el espíritu crítico y la independencia en la toma de decisiones"

\subsection{Visitadores médicos}

Normalmente, el primer contacto entre la industria farmacéutica y los médicos suele tener lugar por medio de los representantes comerciales de esta. La visita médica se configura como el punto de unión entre la Industria y los médicos, es el principal medio por el que la farmacéutica hace llegar al médico la información comercial y técnica de sus nuevos productos, además de todo tipo de obsequios, algunos de ellos de escaso valor —normalmente, material de oficina--, y otros con un gran coste económico, como son suscripciones a revistas, ejemplares de libros científicos e invitaciones a los congresos antes aludidos.

Los visitadores son el elemento más "humano" de toda la estrategia comercial de las farmacéuticas que además, actúa en una relación directa de persuasión con los médicos. A consecuencia de ello y, como forma de garantizar el mayor éxito de su labor, reciben una esmerada formación en técnicas psicológicas y de marketing cuya puesta en práctica sobre los médicos, coincidiendo con la opinión de Altisent, pueden incluso llegar a menoscabar la dignidad de estos ${ }^{57}$.

Aunque pueda parecer que la aceptación de un bolígrafo, una pelota u otro objeto de ínfimo valor, en nada compromete la independencia de los profesionales, lo cierto es que genera un sentimiento de deuda implícita y de simpatía hacia los visitadores que pone en jaque la imparcialidad de los prescriptores. De igual manera, afecta de forma directa a la imagen proyectada por los médicos, mermando la confianza que en ellos depositan los pacientes.

Además, no existe ningún argumento que objetivamente pueda justificar la necesidad de aceptar dichos presentes. En relación con recibir formación financiada por las farmacéuticas, los médicos pueden escudarse en la falta de medios económicos de la institución de la que forman

\footnotetext{
${ }^{56}$ CAROT, G., VALlÈS, X., BONMATÍ, M., GISPERT, B., TARRUELLA, M. D. y ROVIRA, J., "El conflicto de intereses en los profesionales de la salud", op. cit.

${ }^{57}$ ALTISENT, R., "La relación con la industria farmacéutica: una cuestión ética de alta prevalencia en medicina de familia”. Atención primaria, núm. 32, 2003, pp. 106-109.
} 
parte o en lo paupérrimo de sus retribuciones, sin embargo, en relación con estos objetos publicitarios, cuyo valor es irrisorio, esta excusa no es válida ${ }^{58}$. Al contrario de lo que pudiera parecer, el coste inmaterial que para un médico tiene aceptar estos regalos supera con creces al valor de los mismos.

Igualmente, el número de horas que los profesionales invierten en atender a estos profesionales afecta de manera inversamente proporcional a la duración de las consultas con los pacientes, que ya vienen siendo ajustadas por exigencias de la configuración del sistema de salud, lo que devalúa la calidad de la atención médica que los ciudadanos recibimos ${ }^{59}$.

Sin embargo, la visita médica sigue considerándose por la mayoría de los profesionales como algo positivo. Para algunos profesionales, incluso se instaura como una de las principales formas de actualización en materia de fármacos y tratamientos ${ }^{60}$. Dicho esto, llama la atención que, tras un estudio publicado en 2003, en el que se analizaron 472 productos presentados por los visitadores en un total de 308 visitas, solo el 5,1\% eran nuevos fármacos propiamente dichos $\mathrm{y}$, únicamente el 1,5\% implicaban alguna novedad en cuanto a las indicaciones o vías de administración ${ }^{61}$.

Pese a estos datos, somos conscientes de que no podemos negar la labor de los visitadores en la difusión de los avances farmacológicos, pero resulta prácticamente imposible otorgar a dicho conocimiento una credibilidad absoluta. Inevitablemente, dicha información se presenta sesgada, por mucho que se cumpla con las exigencias de transparencia y rigor que el Código de Buenas Prácticas provee ${ }^{62}$.

Para más abundamiento, existen estudios que señalan que la mayoría de las veces, el médico atiende a estos profesionales por educación y respeto a su persona o, incluso, por la relación de amistad que, con el tiempo, puede llegar a unirlos ${ }^{63}$. De esta manera, vemos que solo una ínfima parte de dichas visitas se consienten por razones técnicas o científicas.

De hecho, cuando se pregunta a los médicos sobre qué es lo que más valora o le llama la atención a la hora de relacionarse con estos visitadores, un estudio publicado por la revista de Farmaindustria ${ }^{64}$, revela que la mayoría de ellos se centraban en cuestiones como "el aspecto físico, la relación personal y la capacidad de comunicación, por encima de las relacionadas con la capacidad científico-técnica: rigor, calidad y contenido de los materiales que entregan, o competencia científica".

\footnotetext{
${ }^{58}$ MARTÍN MORENO, S., "Ética de la prescripción. Conflictos del médico con el paciente, la entidad gestora y la industria farmacéutica", op. cit.

${ }^{59}$ ALTISENT, R., "La relación con la industria farmacéutica: una cuestión ética de alta prevalencia en medicina de familia", op. cit.

${ }^{60}$ CAROT, G., VALlÈS, X., BONMATÍ, M., GISPERT, B., TARRUELLA, M. D. y ROVIRA, J., "El conflicto de intereses en los profesionales de la salud", op. cit.

${ }^{61}$ BAENA DÍEZ, J. M., LÓPEZ MOMPÓ, C., LÓPEZ GOSP, D., MARTÍNEZ MARTÍNEZ, J. L., ELLACURÍA TORRES, A. y FUENTES RODRÍGUEZ, S.,” Buenos días, señor Visitador. ¿Algo nuevo que contar? Análisis de las especialidades farmacológicas presentadas por la industria farmacéutica en un área básica de salud". Atención Primaria, núm. 32, 2003, pp. 557-561.

62 RUBIO MONTAÑ́́S, M. L. y CORDÓN, F., "Relación con la industria farmacéutica: ¿un dilema ético?" Atención Primaria, núm. 25, 2000, pp. 135-136.

${ }^{63}$ ALTISENT, R., "La relación con la industria farmacéutica: una cuestión ética de alta prevalencia en medicina de familia”, op. cit.

${ }^{64}$ MADRIDEJOS MORA, R., "La regulación de la visita médica: necesaria pero no suficiente". Atención Primaria, núm. 32, 2003, pp. 562-563.
} 


\subsection{Revistas científicas}

Las revistas científicas son el principal medio de comunicación y divulgación de las diferentes novedades o conclusiones a las que se llega en la investigación biomédica. Los artículos que en ellas se publican son la principal fuente de innovación de los profesionales de la medicina $^{65}$.

En esta materia debemos centrarnos en aquellos artículos que se publican en las revistas como fruto de una determinada investigación o ensayo, cuyo autor presenta algún tipo de relación con la Industria, los cuales inciden en la calidad de aquella innovación y actualización de los médicos.

Ello se encuentra íntimamente relacionada con la presencia de los laboratorios farmacéuticos en el ámbito de la investigación. "La investigación científica es una actividad inherente a la industria farmacéutica, que basa su propio progreso en el desarrollo de nuevos fármacos y nuevas técnicas de diagnóstico" "66. Además, la investigación biomédica y, particularmente los ensayos clínicos, son ámbitos sumamente costosos en los que, pese a la calidad de los investigadores, las instituciones públicas se encuentran desbancadas por los medios de los que disponen los sujetos privados.

El principal motivo que hace dudar del rigor y objetividad de estas publicaciones es el sesgo del que generalmente adolecen las mismas. Este sesgo puede aparecer como consecuencia de diversas tácticas. Principalmente el sesgo deriva de la omisión de datos negativos, las empresas se limitan a publicar los resultados positivos de los ensayos que llevan a efecto, sin dejar constancia del número de intentos fallidos que han acompañado a los que desprenden un resultado favorecedor. Esto implica que la interpretación que se puede llegar a hacer de esos datos jamás va a ser rigurosa ${ }^{67}$.

Ello en el caso de que los datos lleguen a publicarse, pues varios estudios muestran la tendencia de la Industria a no publicar o a retrasar la publicación de determinados estudios, amparándose en la propiedad industrial o en los intereses comerciales, incluyendo aquellos estudios que se han utilizado para conseguir la autorización necesaria para comercializar un producto $^{68}$.

De igual manera, la naturaleza de los ensayos clínicos hace que pueda producirse sesgo desde el primer momento en que estos se plantean: en numerosas ocasiones el número de sujetos participantes en los estudios es verdaderamente inferior al necesario para que se pueda dar un mínimo de credibilidad ${ }^{69}$; en otras ocasiones, estos resultados positivos se obtienen con métodos como "la selección de poblaciones específicas o la comparación con productos de la

\footnotetext{
${ }^{65}$ CAROT, G., VALLÈS, X., BONMATÍ, M., GISPERT, B., TARRUELLA, M. D. y ROVIRA, J., "El conflicto de intereses en los profesionales de la salud", op. cit.

${ }^{66}$ CAROT, G., VALlÈS, X., BONMATÍ, M., GISPERT, B., TARRUELLA, M. D. y ROVIRA, J., "El conflicto de intereses en los profesionales de la salud", op. cit. p. 10.

${ }^{67}$ GARCÍA-VALDECASAS CAMPEL, J. y VISPE ASTOLA, A., "La raya en la arena: la Psiquiatría entre la ética y la industria farmacéutica". Norte de Salud Mental, núm. 13, 2015, pp. 33-43.

${ }^{68}$ PEIRÓ, S., GARCÍA-ALTÉS, A., MENEU, R., LIBRERO, J. y BERNAL, E., "La declaración del conflicto de intereses en las publicaciones científicas. ¿Tiempo para las luces y los taquígrafos en la trastienda de la investigación financiada por la industria?". Gaceta Sanitaria, núm. 14, 2000, pp. 472-481.

${ }^{69}$ GARCÍA-VALDECASAS CAMPEL, J. y VISPE ASTOLA, A., "La raya en la arena: la Psiquiatría entre la ética y la industria farmacéutica", op. cit.
} 
competencia utilizados de forma inadecuada"70. De igual manera, la metodología utilizada para el análisis de los datos puede no ser adecuada y, en consecuencia, la interpretación de dichos datos resultantes puede ser "maquillada" para conseguir resultados más favorables ${ }^{71}$.

Otra de las prácticas que pueden causar una gran influencia en la decisión de los profesionales consiste en publicar, de manera simultánea o muy continua, diferentes artículos sobre un mismo producto, con conclusiones similares, en varias revistas de forma que se llegue a "cuasi-monopolizar" la literatura existente en dicha materia concreta. En este sentido, nos recuerdan Carot, y otros lo acontecido en 2004 en relación con la Sertralina, momento en que los artículos publicados por la empresa que la comercializaba llegaron a suponer entre un $18 \%$ y un $40 \%$ del total de las publicaciones sobre esta molécula.

En este caso concreto, además, la mayoría de los artículos que se publicaron estaban ya redactados antes de "adjudicárseles" un autor ${ }^{72}$. La contratación de redactores profesionales por las farmacéuticas, comúnmente denominados "autores fantasmas", para la producción de artículos científicos que luego serán publicados bajo la autoría de profesionales expertos es una práctica bastante común. En estos casos, el interés que lleva a los expertos a firmar dichos artículos tiende a ser de tipo académico — reconocimiento académico, prestigio, afán por sumar publicaciones - que económico, aunque el económico no ha de ser totalmente descartado. Dicho esto, aunque dicha actuación se inspire en una consecución de un interés legítimo que podría calificarse como secundario, hemos de coincidir con Peiró, García-Altés, Meneu, Librero y Bernal en que esta práctica se aleja de la figura del conflicto de intereses y se aproxima al fraude científico.

Como una forma de evitar, más bien pailar, los conflictos relacionados con la publicación de este tipo de artículos, las principales revistas y asociaciones de editores del panorama mundial, encabezadas por The New England Journal of Medicine, han ido introduciendo mecanismos dirigidos a combatirlos. La mayoría de estos se refieren a la necesidad de publicar las relaciones que puedan tener los autores de los artículos con la industria farmacéutica, particularmente las de tipo económico; otras iniciativas resultan mucho más restrictivas, llegando incluso a denegar la publicación de este tipo de artículos ${ }^{73}$.

Salvando las distancias, estas medidas de publicidad de los conflictos de intereses nos recuerdan a los anuncios de las cajetillas de tabaco que advierten de los peligros de fumar. Se ha demostrado que tienen una cierta utilidad, pero no resuelven el problema de base. La editorial confía en el efecto disuasorio que tendrá, en la Industria y en los autores con algún conflicto, el tener que someter a exposición pública los mismos y, de las misma manera, espera que dichas advertencias impliquen el surgimiento de una actitud crítica de sus lectores. Mientras tanto, la editorial sigue lucrándose con la publicación de dichos artículos, en vez de potenciar la actuación de sus revisores antes de publicar un determinado artículo.

\footnotetext{
${ }^{70}$ PEIRÓ, S., GARCÍA-ALTÉS, A., MENEU, R., LIBRERO, J. y BERNAL, E., "La declaración del conflicto de intereses en las publicaciones científicas. ¿Tiempo para las luces y los taquígrafos en la trastienda de la investigación financiada por la industria?", op. cit, p. 473.

${ }^{71}$ CAROT, G., VALlÈS, X., BONMATÍ, M., GISPERT, B., TARRUELLA, M. D. y ROVIRA, J., "El conflicto de intereses en los profesionales de la salud", op. cit.

72 CAROT, G., VALLÈS, X., BONMATÍ, M., GISPERT, B., TARRUELLA, M. D. y ROVIRA, J., "El conflicto de intereses en los profesionales de la salud", op. cit.

${ }^{73}$ PEIRÓ, S., GARCÍA-ALTÉS, A., MENEU, R., LIBRERO, J. y BERNAL, E., "La declaración del conflicto de intereses en las publicaciones científicas. ¿Tiempo para las luces y los taquígrafos en la trastienda de la investigación financiada por la industria?", op. cit.
} 
Del mismo modo, estas declaraciones han ido perdiendo fuerza con la reiteración de las mismas, "se han ido convirtiendo en una mera rutina, asumida como parte del proceso burocrático de la publicación" 74 . Incluso, podría afirmarse que normalizan el problema de los conflictos de intereses.

Desde otro punto de vista, teniendo en cuenta la naturaleza potencial del conflicto de intereses, hemos de considerar la posibilidad de que no todos los investigadores que tienen un nexo común con la industria farmacéutica - ya sea por motivos económicos o puramente académicos - van a sucumbir ante un conflicto de intereses. Muchos de ellos mantendrán su integridad intacta, desempeñando su labor de acuerdo con los principios técnicos, científicos y morales de su profesión, dirigiendo su actuación a la consecución de los objetivos de esta y apartándose de todo aquello que implique una desviación ética. Por esta razón, creemos que sería más conveniente incluir, junto con la declaración de las relaciones que lo unen a la Industria, la metodología y criterios científicos utilizados para evitar que dichas relaciones condicionen su trabajo ${ }^{75}$.

Sobre esta base, merece ser mencionada la labor del Committee on Publication Ethics, creado en 1997 y al que se han adherido revistas y editores de todo el mundo. Esta institución ha publicado varias guías de actuación, con directrices para enfrentar los conflictos éticos que puedan surgir en todo tipo de publicaciones desde la óptica de los diferentes sujetos que intervienen en las mismas. Sus medidas son reseñables pues, como se puede ver en su página web, no solo se dirigen a establecer medidas utilitaristas como lo es la necesidad de transparencia de los conflictos de interés, sino que fomenta la educación en la materia y el debate entre los diferentes actores, lo que potencia los valores propios de la ética mediante la sensibilización sobre la cuestión ${ }^{76}$.

Todo lo expuesto implica que, aquel médico que caiga en la ingenuidad de pensar que aquellos resultados publicados son totalmente fiables, por el mero hecho de haber sido publicados en X revista, está atentando contra su propia independencia. Por el contrario, el cumplimiento diligente del fin último de su profesión obliga al médico a no confiar ciegamente en dichas publicaciones ${ }^{77}$.

\subsection{Guías de práctica clínica}

La popularidad que alcanzaron estos instrumentos en los años 90 desembocó en que instituciones, asociaciones científicas y, por supuesto, la industria farmacéutica se "subieran al carro" de la elaboración de guías de práctica clínica ${ }^{78}$. La proliferación de las mismas, lejos de enriquecer su contenido, ha llevado a la desvirtualización de la figura, amparando bajo el

\footnotetext{
${ }^{74}$ CAROT, G., VALlÈS, X., BONMATÍ, M., GISPERT, B., TARRUELLA, M. D. y ROVIRA, J., "El conflicto de intereses en los profesionales de la salud", op. cit. p. 14.

75 PEIRÓ, S., GARCÍA-ALTÉS, A., MENEU, R., LIBRERO, J. y BERNAL, E., "La declaración del conflicto de intereses en las publicaciones científicas. ¿Tiempo para las luces y los taquígrafos en la trastienda de la investigación financiada por la industria?", op. cit.

76 “About COPE”, 2 de mayo de 2020. Disponible en: https://publicationethics.org/about/our-organisation

77 MARTÍN MORENO, S., "Ética de la prescripción. Conflictos del médico con el paciente, la entidad gestora y la industria farmacéutica", op. cit.

${ }^{78}$ De hecho, una consulta rápida a la página de GuíaSalud nos permite ver que, en su catálogo, actualmente se recogen como vigentes un total de 32 guías, cantidad que se multiplica por cuatro al comprobar su histórico
} 
nombre de guías de práctica médica figuras con escaso rigor científico que formalmente distan mucho de ser tales ${ }^{79}$.

Pese a que muchos médicos se muestran reticentes a la utilización de estas guías, principalmente porque se consideran instrumentos excesivamente rígidos de difícil traslación a los complejos casos reales, las mismas se configuran como un poderoso instrumento de condicionamiento de la práctica médica de aquellos médicos que sí las utilizan ${ }^{80}$.

Aunque resulta bastante difícil identificar y cuantificar la incidencia que las farmacéuticas tienen sobre estas guías, así como los beneficios que llegan a obtener, lo cierto es que la mayoría de los autores de las mismas presentan alguna relación con la industria farmacéutica que puede situarlos en un latente conflicto de intereses ${ }^{8182}$.

Una de las materias que más preocupa, en relación con el peso de las empresas farmacéuticas en estas guías, es la de los cambios en las definiciones de las enfermedades y la inclusión de nuevas enfermedades ${ }^{83}$. En los últimos años se ha observado una tendencia en las guías a revisar ciertas enfermedades, ampliando los límites de algunas de ellas —enfermedad renal crónica, el trastorno por déficit de atención con hiperactividad, la osteoporosis-, lo que se traduce en un aumento de la cartera de clientes de aquellas empresas que suministran los tratamientos para aquellas enfermedades ${ }^{84}$.

Aunque existan sectores que llegan a considerar positivas estas ampliaciones, bajo el pretexto de la detección precoz de enfermedades, lo cierto es que la mayoría de dichas ampliaciones provienen de guías de práctica cuyos autores tienen una relación con la Industria. De hecho, cuando el Grupo de Trabajo de Sobrediagnóstico de la Guidelines International Network, se propuso examinar dichas cuestiones, fue consciente de que no existía ningún tipo de pautas que regulasen los criterios sobre los que ha de hacerse dicha ampliación para que la misma pueda considerarse adecuada ${ }^{85}$.

${ }^{79}$ RUMBO PRIETO, J. M., ARANTÓN AREOSA, L., RAÑA LAMA, C. D., CORTIZAS REY, J. S. y SÁNCHEZ GÁLVEZ, J., "Independencia editorial y conflictos de interés en guías de práctica clínica sobre lesiones dermatológicas”. Enfermería Dermatológica, núm. 26, 2015, pp. 25-33.

${ }^{80}$ ATIENZA, G., BAÑERES, J. y GRACIA, F., "Guías de práctica clínica y atención primaria. Informe SESPAS 2012”. Gaceta Sanitaria, núm. 26, 2012, pp. 113-117.

${ }^{81}$ NORRIS, S. L., HOLMER, H. K., OGDEN, L. A., BURD, B. U. y MINTZES, B., "Conflict of Interest in Clinical Practice Guideline Development”. A Systematic Review. PLoS ONE, núm. 6, 2011, pp. 1-6.

82 Así lo muestra un esclarecedor estudio publicado en la Journal of the American Medical Association. En él se entrevistó a 192 expertos, quienes habían participado en la elaboración de un total de 144 guías, de los cuales solo dieron respuestas computables en el estudio un 52\%. El 87\% reconoció que tuvo algún tipo de interacción con la Industria (el 58\% reconocía haber recibido financiación para sus investigaciones y el $38 \%$ haber tenido una relación laboral o de asesoramiento con alguna compañía). Del mismo modo, el 59\% tenía algún tipo de relación con la compañía cuyos productos se recomendaban en la guía en la que participó, además, en el $96 \%$ de esos casos la relación era anterior a la elaboración de la guía. Solo el $7 \%$ creía que sus recomendaciones podrían verse afectadas por sus relaciones con la Industria, mientras que el 19\% creía que las relaciones de sus compañeros con aquella influenciaban las recomendaciones de estos (Choudhry, Stelfox, y Detsky, 2002).

${ }^{83}$ CAROT, G., VALLÈS, X., BONMATÍ, M., GISPERT, B., TARRUELLA, M. D. y ROVIRA, J., "El conflicto de intereses en los profesionales de la salud", op. cit.

${ }^{84}$ MOYNIHAN, R., BRODERSEN, J., IONA HEATH, I., JOHANSSON, M., KUEHLEIN, T., MINUÉ-LORENZO, S., . . GLASZIOU, P., "Reforming disease definitions: a new primary care led, people-centred approach". BMJ Evidence-Based Medicine, núm. 24, 2019, pp. 170-173.

85 DOUST, J., VANDVIK, P. O., QASEEM, A., MUSTAFA, R. A., HORVATH, A. R., FRANCES, A., ALANSARY, L., BOSSUYT, P., WARD, R. L., KOPP, I., GOLLOGLY, L., SCHUNEMANN, H., GLASZIOU, P. y GUIDELINES INTERNATIONAL NETWORK (G-I-N)., "Preventing Overdiagnosis Working Group. Guidance for Modifying the Definition of Diseases". A Checklist. JAMA internal medicine, núm. 177, 2017, pp. 1.020-1.025. 
El hecho de que no existiera ninguna pauta empírica o científica que condicionase dichas modificaciones nos hace pensar, más que en los posibles beneficios para los pacientes, en el indudable lucro para los laboratorios farmacéuticos. Y es que, una ampliación no justificada de los sujetos que han considerarse afectados por una determinada enfermedad acarrea consecuencias desastrosas para los pacientes y para la sostenibilidad del sistema de salud. Los pacientes son sobrediagnosticados y tratados innecesariamente, convirtiendo a pacientes inicialmente sanos en enfermos, con el consiguiente riesgo para su salud que ello implica ${ }^{86}$.

Ante esta realidad, dicho Grupo de Trabajo, elaboró la Guidance for Modifying the Definition of Diseases. Una Checklist, donde incluyen una lista de 8 ítems que habrían de verificarse para justificar la revisión de la enfermedad, con la finalidad de racionalizar dichas modificaciones, entre ellos encontramos: los cambios que se proponen, la cuantificación de las personas afectadas, los beneficios y daños potenciales y el balance de los mismos, etc ${ }^{87}$.

Entendemos que los conflictos de intereses presentes en estas guías son uno de los problemas de base en lo que hace a los conflictos éticos en el ámbito médico, particularmente en lo que se refiere a la delimitación de qué ha de entenderse por enfermedad.

\section{Vías para una correcta resolución de las situaciones de conflicto}

El carácter inconsciente de la mayoría de los conflictos de intereses provocados por las situaciones examinadas dificulta sobremanera la detección y gestión de dichos conflictos. La mayoría de las veces la trascendencia ética de los mismos pasa inadvertida confundiéndose con el resto de decisiones que ha de tomar el médico.

Por supuesto, la mejor arma para combatir un conflicto de intereses es su prevención. Para ello, Lama Toro apunta a la necesidad de médicos dotados de una cierta sensibilidad resultado de la educación y el debate abierto en esta materia.

Sentado lo anterior, aquellos conflictos que haya sido imposible eludir deberán ser resueltos mediante el correspondiente juicio ético basado en las virtudes. Sobre esta base, The Royal Australasian College of Physicians, en su Guidelines for ethical relationships between health professionals and industry nos propone una estrategia basada en la reflexión, el reconocimiento, la transparencia, evaluación y decisión.

Los primeros pasos se desarrollarían a nivel interno: el propio sujeto debería de ponderar todos los intereses que motivan cada una de sus actuaciones y qué prioridad tiene cada uno de ellos, deteniéndose en aquellas situaciones susceptibles de desequilibrar la posición que les haya dado a aquellos. Algunos autores apuntan al llamado "test de la confianza" como vía de reconocimiento de tales situaciones ${ }^{88}$. Este test consiste en preguntarse a sí mismo qué grado de incomodidad le supondría el que sus pacientes, o colegas de profesión, descubrieran que tiene un determinado interés secundario en una cuestión. Si dicha respuesta produce un mínimo de incomodidad deberían sonar las alarmas: estamos ante un conflicto de intereses.

${ }^{86}$ MOYNIHAN, R., BRODERSEN, J., IONA HEATH, I., JOHANSSON, M., KUEHLEIN, T., MINUÉ-LORENZO, S., . . GLASZIOU, P., "Reforming disease definitions: a new primary care led, people-centred approach", op. cit.

87 DOUST, J., VANDVIK, P. O., QASEEM, A., MUSTAFA, R. A., HORVATH, A. R., FRANCES, A., ALANSARY, L., BOSSUYT, P., WARD, R. L., KOPP, I., GOLLOGLY, L., SCHUNEMANN, H., GLASZIOU, P., \& GUIDELINES INTERNATIONAL NETWORK (G-I-N)., "Preventing Overdiagnosis Working Group. Guidance for Modifying the Definition of Diseases", op. cit.

${ }^{88}$ LAMA TORO, A., "El médico y los conflictos de intereses". Revista Médica de Chile, núm. 13, 2003, pp. 1.4631.468. 
Una vez identificado entramos en la fase externa de resolución. Aquí la principal estrategia es la publicidad y transparencia plena de la existencia de una confrontación de intereses que puede dar lugar al conflicto. El sujeto debe declarar públicamente aquellas situaciones que lo sitúan en un conflicto de intereses, señalando los concretos intereses, económicos o no económicos, que pudieran comprometerle.

Dada la naturaleza de los conflictos de intereses, se apunta a la necesidad de contar con un agente externo - un Comité Ético, un grupo de evaluación de estos conflictos formado por pares o, de no existir estos medios, un colega de profesión- que evalúe la dualidad de intereses y la actuación del sujeto si esta se encuentra sesgada ${ }^{89}$.

Evaluada la situación de conflicto y las situaciones a que puede dar lugar, se han de acordar estrategias que eviten que el conflicto despliegue efectos maliciosos. Entre ellas se apunta a la inhibición o la recusación, mecanismos ampliamente utilizados y regulados en otros ámbitos, que consisten en la separación del individuo con un interés secundario de la cuestión de que se trate, ya sea por voluntad propia o de los agentes externos. Por último, se ha de comunicar la decisión a todos los posibles afectados y asumir plenamente la responsabilidad que pueda a llegar a derivarse de la misma ${ }^{90}$.

\section{CONCLUSIONES}

La relación entre los profesionales de la medicina y la industria farmacéutica, tal y como se estructura el sistema de producción y distribución de los productos farmacológicos, resulta útil y necesaria. Se trata de dos ámbitos complementarios que requieren el uno del otro para subsistir y alcanzar los fines propios de los unos y la otra. No obstante, lejos las aspiraciones económicas de la Industria han desbordado el respeto debido a los profesionales de salud, quienes se han convertido en el foco de todo tipo de técnicas de promoción de productos farmacéuticos, algunas de la cuales sitúan a los profesionales en una posición de conflicto entre sus diferentes intereses.

Todas las situaciones analizadas en el presente ensayo vinculan al médico con una actuación concreta que le es inducida por la Industria y que pone en riesgo la consecución de aquel fin que le es dado al acceder a la profesión médica: la promoción y cuidado de la salud y vida de los pacientes. Ello implica una quiebra de la independencia del médico y la correlativa pérdida de la confianza que los pacientes depositamos en ellos.

La sociedad estipula un contrato con la medicina, el cual se sustenta sobre la base de la confianza que se deposita en estos profesionales. El médico, por este contrato, se convierte en fiduciario del paciente, quien se encuentra en una situación de inferioridad de conocimientos y de vulnerabilidad. El cumplimiento de los principios y compromisos que informan este contrato es lo que, en esencia, determina la excelencia en la práctica de la profesión.

Por lo tanto, cualquier actuación que se desvincule de dichos objetivos supondrá una vulneración del propio ethos de la profesión y de los compromisos y principios a los que el médico se obliga con la sociedad y que, en esencia, constituyen los fundamentos del profesionalismo. Igualmente, al analizar todas estas cuestiones desde una óptica principialista, vemos que el efecto de esta influencia imposibilita que el acto de la prescripción se ajuste a las exigencias de la excelencia.

\footnotetext{
${ }^{89}$ ARGANDOÑA, A., "Conflicto de intereses: el punto de vista ético”, op. cit.

90 "Guidelines for ethical relationships between health professionals and industry", The Royal Australasian College of Physicians, Sydney, 2018.
} 
Por lo tanto, la solución adecuada de estos conflictos se convierte en una exigencia para todo médico que pretenda hacer valer el bienestar de sus pacientes y, de esta manera, alcanzar la excelencia en el ejercicio de su profesión. En este punto, lo ideal sería evitar cualquier situación susceptible de causar una pugna de intereses en el médico. No obstante, la propia naturaleza inconsciente de estos hace imposible que ello llegue a conseguirse en todos los casos. En aquellos casos en los que sea imposible prevenir la aparición de estos problemas éticos, se requiere de un médico virtuoso, capaz de llevar a cabo el correspondiente juicio introspectivo y de tomar la decisión más adecuada en comunión con los estándares de excelencia requeridos por su profesión.

En cualquier caso, además de una correspondiente sensibilización y educación en virtudes de los médicos, ya sea por las diferentes vías formativas oficiales o a través del currículum oculto de estos, se precisa una actitud activa de cambio por parte todos los agentes que intervienen, de una manera u otra, en el ejercicio de la medicina, que podemos resumir en los siguientes puntos:

- Necesidad de que las universidades proporcionen una formación suficiente en materia de prevención y gestión de conflictos de intereses.

- Potenciar medidas tendentes a eliminar o, como mínimo, reducir la dependencia que el sistema de salud tiene respecto de las compañías farmacéuticas.

- Se ha de dotar a la visita médica de unos contornos que garanticen la dignidad del médico y de los propios visitadores.

- Los responsables de las revistas científicas han de apostar por la objetividad y la transparencia de sus publicaciones.

- Se han de establecer protocolos concretos y minuciosos que reglamenten la elaboración y modificación de las guías de práctica médica.

\section{REFERENCIAS BIBLIOGRÁFICAS}

- ABIM Foundation, ACP-ASIM Foundation, \& European Federation of Internal Medicine. "Profesionalidad médica en el nuevo milenio: un fuero médico", Revista Clínica Española, núm. 202, 2002, pp. 449-452, 3 de abril de 2020. Disponible en https://www.revclinesp.es/es-profesionalidad-medica-el-nuevo-milenio-articulo-13035644

- “About COPE", 2 de mayo de 2020. Disponible en: https://publicationethics.org/about/ourorganisation

- ALTISENT, R., "Ética, bioética y deontología”, Revista bioética, núm. 17, 2009, pp. 363 375, 15 de mayo de 2020. Disponible en http://revistabioetica.cfm.org.br/index.php/revista_bioetica/article/view/504

- ALTISENT, R., "La relación con la industria farmacéutica: una cuestión ética de alta prevalencia en medicina de familia”, Atención primaria, núm. 32, 2003, pp. 106-109.

- Altisent, R., Delgado MARroquín, M. T. y ASTIER PEÑA, M. P., "Conflictos de interés en la profesión médica", Atención Primaria, núm. 51, 2019, pp. 506-511, 28 de febrero de 2020.2 Disponible en https://www.sciencedirect.com/science/article/pii/S0212656719303634

- ARGANDOÑA, A., "Conflicto de intereses: el punto de vista ético", en C. d. Negocios (Ed.), XII Conferencia anual de Ética, Economía y Dirección, 2004, 20 de mayo de 2020. 
Disponible

https://www.ieseinsight.com/fichaMaterial.aspx?pk=1870\&idi=1\&origen=1\&idioma=1

- ATIENZA, G., BAÑERES, J. y GRACIA, F., "Guías de práctica clínica y atención primaria. Informe SESPAS 2012”, Gaceta Sanitaria, núm. 26, 2012, pp. 113-117.

- BAENA DÍEZ, J. M., LÓPEZ MOMPÓ, C., LÓPEZ GOSP, D., MARTÍNEZ MARTÍNEZ, J. L., ELLACURÍA TORRES, A. y FUENTES RODRÍGUEZ, S., "Buenos días, señor Visitador. ¿Algo nuevo que contar? Análisis de las especialidades farmacológicas presentadas por la industria farmacéutica en un área básica de salud", Atención Primaria, núm. 32, 2003, pp. 557-561.

- BEAUChAMP, T. y CHILDRESS, J. F., Principles of biomedical ethics, Oxford University Press, Nueva York, 1983, p. 318.

- BLANCO MERCADÉ, A., "Vida, ética y deontología médica: aclarando conceptos", EIDON: revista de la fundación de ciencias de la salud, núm. 52, 2019, pp. 23-32, 12 de mayo de 2020. Disponible en https://dialnet.unirioja.es/servlet/articulo?codigo=722502

- BORRELl-CARRIO, F., EPSTEIN, R. y PARDELl ALENTÀ, H., "Profesionalidad y professionalism: fundamentos, contenidos, praxis y docencia”, Medicina Clínica, núm. 127, 2006, pp. 337-342, 20 de marzo de 2020. Disponible en https://www.elsevier.es/es-revistamedicina-clinica-2-articulo-profesionalidad-professionalism-fundamentos-contenidospraxis-docencia-13092322

- BUFFO SEQUEIRA, I., ARROYO CASTELÁN, E., HALABE CHEREM, J. y MONROY SAINT MARTIN, M., "El médico y la relación con la industria farmacéutica", Revista CONAMED, núm. 17, 2012, pp. 182-186.

- CARot, G., VAllès, X., Bonmatí, M., GiSPERT, B., TARRUElla, M. D. y ROVIRA, J., "El conflicto de intereses en los profesionales de la salud", Bioètica \& debat: Tribuna abierta del Institut Borja de Bioètica, núm. 81, 2017, pp. 3-25, 20 de mayo de 2020. Disponible en https://dialnet.unirioja.es/servlet/articulo?codigo $=6260187$

- CHOUDHRY, N. K., STELFOX, H. T. y DETSKY, A. S., "Relationships Between Authors of Clinical Practice Guidelines and the Pharmaceutical Industry", JAMA, núm. 287, 2002, pp. 612-617.

- "Código de Buenas Prácticas de la Industria Farmacéutica", España, 2016, 1 de mayo de 2020. Disponible en https://www.codigofarmaindustria.org/servlet/sarfi/codigo/codigo.html

- "Código de Deontología Médica", Organización Médica Colegial de España, 2011, 27 de febrero de 2020. Disponible en: https://www.cgcom.es/codigo_deontologico/files/assets/basic-html/page-2.html

- CORTINA, A., "Universalizar la aristocracia: por una ética de las profesiones", Claves de razón práctica, núm. 75, 1997, pp. 46-52, 28 de marzo de 2020. Disponible en https://www.uis.edu.co/webUIS/es/mediosComunicacion/revistaSantander/revista1/universa lizarAristocracia.pdf.

- COUCEIRO VIDAL, M. A., "Los niveles de la justicia sanitaria y la distribución de los recursos", Anales del Sistema Sanitario de Navarra, núm. 29, 2006, pp. 61-74.

- DE SANTiAgO, M., "Las Virtudes en Bioética Clínica", Cuadernos de Bioética, núm. 1, 2014, pp. 75-91, 15 de marzo de 2020. Disponible en https://libros-revistasderecho.vlex.es/vid/virtudes-bioa-tica-cla-nica-510964678 
- DOUST, J., VANDVIK, P. O., QASEEM, A., MUSTAFA, R. A., HORVATH, A. R., FRANCES, A., AL-ANSARY, L., BOSSUYT, P., WARD, R. L., KOPP, I., GOLLOGLY, L., SCHUNEMANN, H., GLASZIOU, P. y GUIDELINES INTERNATIONAL NETWORK (G-I-N)., "Preventing Overdiagnosis Working Group. Guidance for Modifying the Definition of Diseases", A Checklist. JAMA internal medicine, núm. 177, 2017, pp. $1.020-1.025$.

- GARCÍA-VALDECASAS CAMPEL, J. y VISPE ASTOLA, A., "La raya en la arena: la Psiquiatría entre la ética y la industria farmacéutica", Norte de Salud Mental, núm. 13, 2015, pp. 33-43.

- GENTA-MESA, G. y FLÓREZ, I. D., "Relación médico-industria y los conflictos de interés: aspectos históricos y normativos, impactos negativos y propuestas", IATREIA, núm. 32, 2019, pp. 298-310.

- GILI PASCUAL, A., "Los incentivos en el ámbito sanitario ante el derecho penal", Cuadernos de Política Criminal, núm. 122, 2017, pp. 47-87, 19 de abril de 2020. Disponible en https://app.vlex.com/\#search/jurisdiction:ES/LOS+INCENTIVOS+EN+EL+\%C3\%81MBI TO+SANITARIO+ANTE+EL+DERECHO+PENAL/WW/vid/699933281

- "Guidelines for ethical relationships between health professionals and industry", The Royal Australasian College of Physicians, Sydney, 2018.

- GÓmEZ CÓRDOBA, A. I., LATORRE SANTOS, C. y NEL CARREÑO, J., "Dilemas éticos en las relaciones entre la industria farmacéutica y los profesionales de la salud", Persona y bioética, núm. 11, 2007, pp. 23-38, 5 de marzo de 2020. Disponible en https://dialnet.unirioja.es/servlet/articulo?codigo $=2361049$

- GRACIA, D., "La ética en las instituciones sanitarias: entre la colaboración y el conflicto", La ética en las instituciones sanitarias: entre la lógica asistencial y la lógica gerencial, Fundación Víctor Grifols i Lucas, Barcelona, 2012, pp. 13-21.

- GRACIA, D., "Ética profesional y ética institucional: ¿convergencia o conflicto?", Revista Española de Salud Pública, núm. 80, 2006, pp. 457-467, 10 de abril de 2020. Disponible en http://scielo.isciii.es/scielo.php?script=sci_arttext\&pid=S1135-57272006000500004

- GRACIA, D., "El recto ejercicio profesional, ¿cuestión personal o institucional?: El caso de la atención al enfermo terminal", Quadern CAPS, núm. 23, 1995, pp. 94-98, 10 de abril de $2020 . \quad$ Disponible http://www.sidastudi.org/es/registro/2c9391e41fb402cc011fb43c5e2c27a8

- HidAlgo CARBAllal, A. y GONZÁlez PERNÍA, J., "Ética de la prescripción. Ciencia y conciencia. Primera parte", SEMERGEN: revista española de medicina de familia, núm. 3, 2009, pp. 156-160.

- KIDDER, R. M., How Good People Make Tough Choices: Resolving the Dilemmas of Ethical Living, William Morrow, Nueva York, 1995.

- LAMA TORO, A., "El médico y los conflictos de intereses", Revista Médica de Chile, núm. 13, 2003, pp. 1.463-1.468.

- Ley $29 / 2006$, de 26 de julio, de garantías y uso racional de los medicamentos y productos sanitarios.

- Ley 44/2003, de 21 de noviembre, de ordenación de las profesiones sanitarias. 
- Lizaraso CAPARÓ, F. y BenAVIDES ZÚÑIGA, A., "Ética Médica", Horizonte médico, núm. 18, 2018, pp. 4-8, 26 de febrero de 2020. Disponible en http://www.scielo.org.pe/scielo.php?script=sci_arttext\&pid=S1727-558X2018000400001

- MACINTYRE, A., After virtue: a study in moral theory, Duckworth, Londres, 1985.

- MADRIDEJOS MORA, R., "La regulación de la visita médica: necesaria pero no suficiente”, Atención Primaria, núm. 32, 2003, pp. 562-563.

- MARTÍN MORENO, S. "Ética de la prescripción. Conflictos del médico con el paciente, la entidad gestora y la industria farmacéutica”, Atención Primaria, núm. 116, 2001, pp. 299306.

- MARTÍNEZ NAVARRO, E., "La Ética profesional como proyecto personal y compromiso de ciudadano", en CORREA CASANOVA, M. y MARTÍNEZ BECERRA, P. (eds.), La riqueza ética de las profesiones, RIL Editores, Santiago de Chile, 2010, pp. 23-54.

- MORENO VILlaRES, J. M., "Prudencia, virtud indispensable", Cuadernos de Bioética, núm. 25, 2014, pp. 105-110.

- MOYA BERNAL, A., "Ética de la prescripción", Información terapéutica del Sistema Nacional de Salud, núm. 35, 2011, pp. 57-63.

- MOYNIHAN, R., BRODERSEN, J., IONA HEATH, I., JOHANSSON, M., KUEHLEIN, T., MINUÉ-LORENZO, S., . . . GLASZIOU, P., "Reforming disease definitions: a new primary care led, people-centred approach", BMJ Evidence-Based Medicine, núm. 24, 2019, pp. 170-173.

- NORRIS, S. L., HOLMER, H. K., OGDEN, L. A., BURD, B. U. y MINTZES, B., "Conflict of Interest in Clinical Practice Guideline Development", A Systematic Review. PLoS ONE, núm. 6, 2011, pp. 1-6.

- OPPES, M., “Cuál es el futuro de la deontología médica?”, Medicina y ética: Revista internacional de bioética, deontología y ética médica, núm. 18, 2007, pp. 109-118, 29 de marzo de 2020. Disponible en https://dialnet.unirioja.es/servlet/articulo?codigo=2770553.

- ORIOL, A., "El profesionalismo: asignatura pendiente del sistema educativo médico", EIDON. Revista española de bioética, núm. 33, 2010, pp. 52-57, 30 de marzo de 2020. Disponible en https://www.revistaeidon.es/public/journals/pdfs/2010/33_junio.pdf.

- ORTIZ POMMIER, A., "Gestión clínica y conflicto de intereses", Acta bioethica, núm. 15, 2009, pp. 157-164.

- PEIRÓ, S., GARcía-AltÉS, A., MENEU, R., LiBrero, J. y BERNAL, E., "La declaración del conflicto de intereses en las publicaciones científicas. ¿Tiempo para las luces y los taquígrafos en la trastienda de la investigación financiada por la industria?", Gaceta Sanitaria, núm. 14, 2000, pp. 472-481.

- Real Decreto 1416/1994, de 25 de junio, por el que se regula la publicidad de los medicamentos de uso humano.

- Real Decreto Legislativo 1/2015, de 24 de julio, por el que se aprueba el texto refundido de la Ley de garantías y uso racional de los medicamentos y productos sanitarios.

- RUBIO MONTAÑÉS, M. L. y CORDÓN, F., "Relación con la industria farmacéutica: ¿un dilema ético?”, Atención Primaria, núm. 25, 2000, pp. 135-136. 
- RUMBO PRIETO, J. M., ARANTÓN AREOSA, L., RAÑA LAMA, C. D., CORTIZAS REY, J. S. y SÁNCHEZ GÁLVEZ, J., "Independencia editorial y conflictos de interés en guías de práctica clínica sobre lesiones dermatológicas", Enfermería Dermatológica, núm. 26, 2015, pp. 25-33.

- SAH, S. y FUGH-BERMAN, D., "Physicians under the Influence: Social Psychology and Industry Marketing Strategies", Journal of Law, Medicine and Ethics, núm. 14, 2013, pp. 665-672, 2 de abril de 2020. Disponible en https://papers.ssrn.com/sol3/papers.cfm?abstract_id=2286433

- SÁNCHEZ MARTÍN, M. M., "Profesionalismo", Revista Española de Cirugía Osteoarticular, núm. 47, 2012, pp. 170-180, 10 de marzo de 2020. Disponible en https://dialnet.unirioja.es/servlet/articulo?codigo $=4275610$ 